\title{
EVALUATING THE WATER QUALITY OF SOME WELLS IN AL- RIFAI CITY
}

\author{
${ }^{1}$ Hussein Khalefa Chlaib, ${ }^{2}$ Reyad Shaker Badeh, ${ }^{3}$ Jalal Hamed Ali \\ ${ }^{4}$ Najm Abed Yasir, ${ }^{5}$ Alaa Ibrahim Badi, ${ }^{6}$ Jaber Hameed Muttair \\ 1,2,3,4,5,6 Department of Soil Sciences and Water Resources, Collage of Agriculture, University of Sumer, Dhi-Qar, Iraq
}

\section{Email:hkaldobayany@yahoo.com}

\begin{abstract}
:
Due to the scarcity of water resources at the present time in Thi-Qar governorate, many people and farmers resort to using groundwater and well water for all purposes to meet their daily water needs. Therefore, it is important to evaluate the quality of well water and determine its suitability for different uses. Therefore, the researchers in this study dealt with evaluating some physical and chemical properties of the water of some wells located in Al-Rifai city in Thi-Qar governorate / southern Iraq during the year 2020 for the purpose of assessing the quality of well water. Water samples were collected from 9 wells at different depths, ranging between 1-7 meters. The electrical conductivity, $\mathrm{pH}$, turbidity and the total dissolved salts were measured. The concentrations of some major ions in the water of these wells, represented by chloride, carbonate, bicarbonate, calcium and dissolved oxygen, were also measured. Analytical methods were followed for determining chloride ions, bicarbonate, carbonate and calcium, and measuring total dissolved salts (TDS), pH, electrical conductivity (EC), dissolved oxygen (DO) and the turbidity using the electrical methods. It was found that the concentration of ions in the well water for chloride ranged between (31.6 - $3.8 \mathrm{meq} / \mathrm{L}$ ) and calcium (43.26 - $71.8 \mathrm{meq} / \mathrm{L}$ ), while the bicarbonate values ranged between $(630-160 \mathrm{meq} / \mathrm{L})$. The $\mathrm{pH}$ values ranged between $(7.38-7.5)$ and the EC values between (4.35 - $1.33 \mathrm{mmho} /$ $\mathrm{cm})$, while the values of the TDS ranged between $(2175-666 \mathrm{ppm})$ and the DO values ranged between $(8.85-7.30 \mathrm{ppm})$. The turbidity values ranged between (FTU $105-0.05$ FTU). It was found through the study that the values of some ions were high, while others were within the permissible limits, and this indicates contamination of well water in that area. It was also found that the behavior of that water was a basic behavior. All physical and chemical properties were represented in the form of contour maps to illustrate the general distribution of these values in the wells of the study area.
\end{abstract}




\section{INTRODUCTION}

Groundwater is considered one of the natural water sources and it includes the water that collects in the ground as a result of the leakage of part of the rainwater through the porous layers of the earth, and part of the groundwater flows from the ground automatically in the form of springs or industrial in the form of natural wells (Natural or Artesian wells) (Adam, 1983). Groundwater is used for irrigation and for human and animal drinking, according to its physical and chemical characteristics. The chemical and physical properties of this water change due to geological formations, seasonal changes, well depths, and water withdrawal conditions (Haddad, 1978). Groundwater dissolves varying amounts of salts, and the quality and concentrations of dissolved salts depend on the nature of the ground layers that the groundwater passes through. (Camp and Meserve, 1978) Water pollution is defined as the degradation in the quality of basic natural water as a result of human interference, which makes this water unfit for life and industrial uses (Al-Obaidi and Ajam, 1980, ). The significant increase in water pollution is a result of the increase in population and the progress and development of various industries, as well as due to agricultural interferences as a result of the use of pesticides and chemical fertilizers (Adam, 1983). Human life often depends on groundwater for agriculture, human and animal drinking. In some southern areas of Iraq, dependence on groundwater is $90 \%$ (Al-Zamili and Al-Shahmani, 2005). Study area The study area is located in Al-Rifai district in Thi-Qar governorate/ southern Iraq, between longitude (Long: 46.068047, 46.169216) and latitude (Lat: 31.709238, 31.606093 ), with a total area of about $103 \mathrm{~km}^{2}$. Sedimentology, the region is located within the sedimentary plain of the Mesopotamia, which consists of deposits of different proportions of sand, silt and clay, which represented by sediments of the flood plains (Jassim and Goff, 2006), Figure (1).

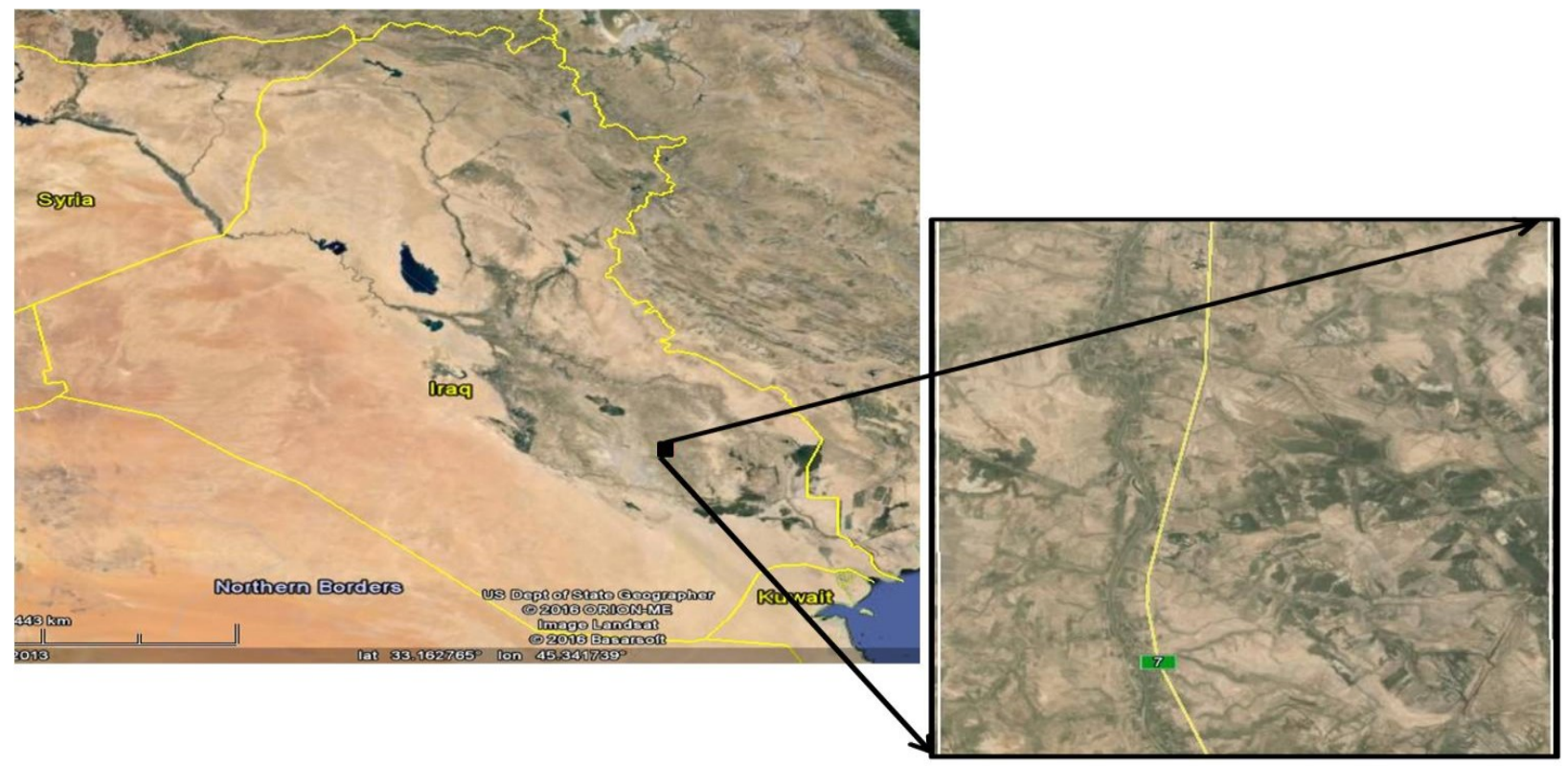

Figure 1: Represents the location of the study area on the map of Iraq. 


\section{Research objective}

Due to the dependence of some residents of Al-Rifai city areas on groundwater in many daily life activities and the sensitivity of this topic to a direct link with the citizen's life, the current study dealt with assessing the water quality of some wells in the city of Al-Rifai and determining its suitability for human, animal and plant uses.

\section{MATERIALS AND METHODS}

\section{-Modeling method}

Nine well water samples were taken from the wells in the study area (Figure 2 and Table 1) with three replications for each sample. The water samples were placed in closed half-liter plastic bottles and stored in the refrigerator at an appropriate temperature.

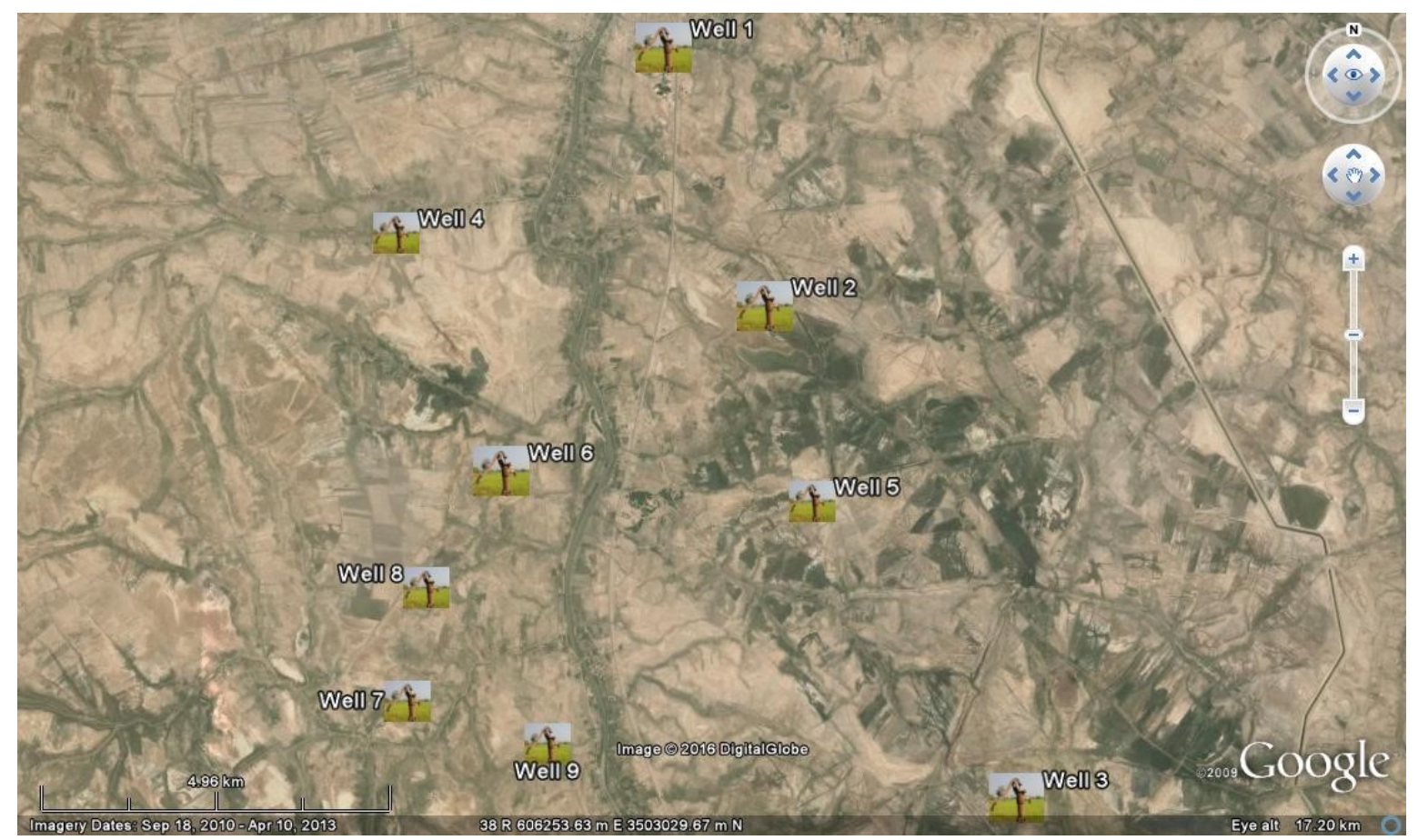

Figure (2) Shows the locations of the wells used in the study. 
Table (1) Represents the coordinates of the studied wells.

\begin{tabular}{|c|c|c|c|}
\hline Well No. & Lat. & Long. & Depth to water (m) \\
\hline \hline 1 & ${ }^{\circ} 31.706032$ & ${ }^{\circ} 46.113056$ & 1.8 \\
\hline \hline 2 & ${ }^{\circ} 31.672831$ & ${ }^{\circ} 46.128501$ & 1.6 \\
\hline \hline 3 & ${ }^{\circ} 31.609841$ & ${ }^{\circ} 46.166509$ & 3 \\
\hline \hline 4 & ${ }^{\circ} 31.682012$ & ${ }^{\circ} 46.072861$ & 3.5 \\
\hline \hline 5 & ${ }^{\circ} 31.647760$ & ${ }^{\circ} 46.135705$ & 3 \\
\hline \hline 7 & ${ }^{\circ} 31.651461$ & ${ }^{\circ} 46.088917$ & 3 \\
\hline \hline 8 & ${ }^{\circ} 31.622000$ & ${ }^{\circ} 46.075050$ & 2.8 \\
\hline \hline 9 & ${ }^{\circ} 31.636486$ & ${ }^{\circ} 46.077725$ & 2.5 \\
\hline
\end{tabular}

\section{-Measurement of Chloride}

Chloride is a chlorine ion in its negative form $\mathrm{Cl}^{-}$, meaning that it is a negative ion as it can combine with the positive fissures (metals), forming its salts, which are found in the form of mineral salts. Chloride enters the human body through water and food, and its amount excreted from human body is about (6) g / person / day, and affects plants and aquatic organisms present in the water source and makes the taste of water unpalatable if it exceeds its limits and also affects the osmotic pressure of the organism. Chloride is found in most water sources under natural conditions as a result of the melting of sedimentary and igneous rocks in water. Chloride was estimated in water using the (Mohrs method). This method depends on the formation of insoluble silver chromates when the chloride is titrated with silver nitrate using the potassium chromate indicator $\left(\mathrm{K}_{2} \mathrm{CrO}_{4}\right)$.

\section{-Preparation of materials}

Silver Nitrate $0.01 \mathrm{~N}\left(\mathrm{AgNO}_{3}\right)$ was prepared by dissolving $0.42 \mathrm{~g}$ of dry material in a quantity of water, then the volume was supplemented with $250 \mathrm{ml}$ of distilled water. Potassium chromate indicator is prepared by dissolving 20 $\mathrm{g}$ of the substance in an amount of water and the volume is supplemented with $200 \mathrm{ml}$ of distilled water.

\section{-Work method}

The blanck was prepared by taking $5 \mathrm{ml}$ of distilled water and adding 4 drops of potassium chromate indicator to it and titrate with silver nitrate $(0.01 \mathrm{~N})$ until the color changed from yellow to orange according to the volume of silver nitrate coming from the burette. $5 \mathrm{ml}$ were taken from each sample and added 4 drops from the potassium 
chromate indicator to each sample, then titrate with silver nitrate until the color changed from yellow to orange to obtain the volume of silver nitrate and calculate the amount of chloride present in each sample as shown in (Table 1) according to the equation:

$\mathrm{Cl} \mathrm{Meq} / \mathrm{I}=\left(\left(\mathrm{AgNO}_{3}\right.\right.$ volume of the sample- $\mathrm{AgNO}_{3}$ volume of the blank $* \mathrm{AgNO}_{3}$ Normality $) /($ water sample volume)) x 1000

\section{-pH measurement}

It is a measure of acidity under normal conditions of temperature and pressure (Langmuir, 1997), pH is considered as one of the important variables that must be measured and has great importance in quantitative calculations of saturation states (Appelo, 1999). Also, it is the dominant factor in most reactions, as well as measuring $\mathrm{pH}$ in the field is important for assessing water quality due to its relation with the erosion and taste (Mazor, 1990).

\section{-Work method}

First, washing the electrodes of the $\mathrm{pH}$ meter device well with distilled water, then the device was calibrated through the calibration solutions of the device. After washing the beaker well, in which the sample (water) was placed, and the electrode was placed inside the sample and waited until the device reading. The reading was recorded and the electrodes of the device were washed after and before each measurement.

\section{$\underline{\text {-EC measurement }}$}

The type and concentration of salts differs in the water and according to the source of the water (rain, groundwater ... etc). Rainwater is considered one of the least sources of water in terms of its containment of salts, followed by the river water and then groundwater (Al- Saadi et al.,2000) The importance of EC measurement comes from its use in many hydrological, hydrochemical and agricultural applications. Also, many of the standard specifications depend on electrical conductivity due to its connection with salinity. EC measurement is a quick way to estimate salinity through the mathematical relationships that connected between them (Todd, 1980). EC depends on the water temperature, increasing the water temperature by one degree Celsius causes an increase in EC by $2 \%$. Also, the EC increases by increasing the dissolved salts (Detay, 1997).

\section{-Work Method}

The electrodes of the EC meter device were washed well to get rid of all salts accumulated on the electrode. After washing the beaker well, the sample to be measured was placed in it. The electrodes of the device were immersed in the sample and we wait for the device to take the reading. The electrodes of the device are washed after and before each measurement. 


\section{$\underline{\text {-Measurement of total dissolved salts (T.D.S) }}$}

TDS includes the total dissolved salts (both ionized and non-ionized) in solution and does not include suspended and colloidal substances and dissolved gases. In practice, TDS are those materials that pass through a filter material (filter paper) and are encapsulated after the evaporation process. generally, TDS consists of the total of negative and positive ions. The concentration of dissolved ions in natural waters depends on the type of rocks and soils that are in contact with them and on the time period that the contact process takes (Hem, 1970).

\section{-Work method}

The beaker was washed well and the sample was placed in. After washing the electrodes of the TDS device with distilled water to get rid of the salts in it, the electrodes are immersed in the sample and we wait for the device to read. it is so important for the electrodes to wash before and after each measurement.

\section{$\underline{\text {-Measurement of turbidity }}$}

It indicates the obstruction of suspended materials for the passage of light through the water. Turbidity is formed as a result of the presence of a proportion of suspended matter and water float organisms. The degree of turbidity depends on the amount, type, color and size of suspended substances. It is important to estimate the turbidity in the water because of its importance in the growth of fish, as it has been observed that the turbidity of the water causes some problems for shallow fish ponds when it blocked sunlight from reaching plant organisms, therefore these plants will not able to producing oxygen (Naseem, 2007).

\section{-Work method}

$10 \mathrm{ml}$ of the sample was withdrawn by pipette and putted into the test tube of the turbidity device, after cleaning the tube well with a clean piece of cloth and then the turbidity device was calibrated. The test tube was placed inside the device chamber and the device is turned on and we wait until the readings are taken. The tube is washed with distilled water before and after each measurement. .

\section{$\underline{\text {-Measurement of carbonate and bicarbonate }}$}

The natural source of alkalinity is limestone and dolomite sedimentary rocks from which carbon and sodium, calcium, and magnesium bicarbonate, are generated. Bicarbonate represents the general or predominant form of the base compounds. The interaction of water with limestone results in bicarbonate. 


\section{-Work method}

$10 \mathrm{ml}$ was taken from each sample and 3 drops of phenonphthalein were added to each sample, and no pink color was noticed, indicating the absence of carbonates, meaning that the value of $(\mathrm{Y})$, which is the volume of acid required for titrations, is equal to zero, as shown in Table (1).Then, 5 drops of orange methyl were added to the same solution and titrated with $1 \mathrm{~N}$ of sulfuric acid until the color changed from yellow to pink to obtain the volume of acid coming down from the burette $(\mathrm{Z})$, the amount of bicarbonate in the sample is calculated from the following equation:

\section{$\mathrm{HCO}_{3}{ }^{-} \mathrm{meq} / \mathrm{L}=((\mathrm{Z}-2 \mathrm{Y})) \times \mathrm{H}_{2} \mathrm{SO}_{4}$ Normality $) /(\mathrm{ml}$ in a liquot $) \times 1000$}

\section{-Dissolved oxygen measurement (DO)}

DO represents the dissolved oxygen in water and the oxygen factor plays an important role in the vertical distribution of animals. It was found that $95 \%$ of all animals are located in the upper $2 \mathrm{~cm}$ and $5 \mathrm{~cm}$ of the upper layer, respectively. Also, the decrease in oxygen concentration has a great effect on the degree of tolerance to other environmental factors such as temperature and salinity (Al-Saadi et al. 2000).

\section{-Work method}

The DO device electrodes were washed well with distilled water, submerging the device electrodes in the sample, waiting for the device to read, and washing the electrodes before and after each measurement.

\section{-Calcium measurement}

Calcium is one of the most abundant alkaline earth elements in the earth's crust, and it is an essential element for plants and animals. Calcium ion is produced from dissolving processes of carbonate and gypsum sedimentary rocks, as well as from erosion of pyroxene and amphibole minerals group and feldspar (Hem, 1989)

\section{-Method of work}

EDTA $(0.01 \mathrm{~N})$ was prepared by dissolving $0.73 \mathrm{~g}$ of the substance in a volume of distilled water and then the volume was supplemented to liter. $5 \mathrm{ml}$ were taken from each sample, $20 \mathrm{ml}$ of distilled water were added to each sample, then 5 drops of sodium hydroxide $\mathrm{NaOH}(4 \mathrm{~N})$ were added and a little phenonphthalein indicator was added and then titrated with EDTA until the color changed from pink to purple to know the volume of EDTA goes down from the burette, calculation the amount of calcium in each sample is according to the following equation:

Meq Ca $/$ L = ((EDTA normality x EDTA volume goes down from burette) / sample volume $)$ x 1000 


\section{RESULTS AND DISCUSSION}

The results of the current study, which included measuring some chemical and physical variables for the water of some wells in Al-Rifai district, are shown in Table (2). It is noticed that the highest value of the $\mathrm{pH}$ was 7.38 , while its lowest value was 7.5. This is due to the increase in the amount of dissolved salts in the water, the acidity increases with the increase of water salts. Iraqi soils are rich in calcium salts, and hence they are the predominant salts in water that lead to giving Iraqi water the basic characteristic (Hassan, 2004). Also, EC was studied, the highest value was $4.35 \mathrm{mmhos} / \mathrm{cm}$ and the lowest value was $1.33 \mathrm{mmhos} / \mathrm{cm}$. The reason for the high values of the $\mathrm{EC}$ is due to the high ratio of salts. Ground water contains high concentrations of salts due to its long stay with rocks, as well as the geological nature and salt content of the lands were the wells excavated (SDWF, 2008). The highest value of chloride concentration was $31.6 \mathrm{meq} / 1$ and the lowest value was $3.8 \mathrm{meq} / 1$, this is due to the increase in salts in the well's surrounding soil. Among these salts are sodium chloride $\mathrm{NaCl}$, potassium chloride $\mathrm{KCl}$, Calcium chloride $\mathrm{CaCl}_{2}$, these salts are the problem with approximately $0.05 \%$ of the lithosphere (WHO, 1996).

Table No. (1) shows the values of each of the chemical and physical characteristics of the studied water samples for the studied wells.

\begin{tabular}{|c||c|c|c|c|c|c|c|c||c|c||}
\hline $\begin{array}{c}\text { TUR } \\
\text { FTU }\end{array}$ & $\begin{array}{c}\text { DO } \\
\%\end{array}$ & $\begin{array}{c}\text { DO } \\
\text { ppm }\end{array}$ & $\begin{array}{c}\text { TDS } \\
\text { ppm }\end{array}$ & $\begin{array}{c}\mathrm{HCO}_{3} \\
\mathrm{meq} / 1\end{array}$ & $\begin{array}{c}\mathrm{CO}_{3} \\
\mathrm{meq} / 1\end{array}$ & $\begin{array}{c}\mathrm{Cl} \\
\mathrm{meq} / 1\end{array}$ & $\begin{array}{c}\mathrm{Ca} \\
\mathrm{meq} / 1\end{array}$ & $\begin{array}{c}\mathrm{EC} \\
\mathrm{Ms} / \mathrm{cm}\end{array}$ & $\mathrm{pH}$ & $\begin{array}{c}\text { Well } \\
\text { No. }\end{array}$ \\
\hline \hline 5.73 & 80.5 & 7.30 & 666 & 300 & 0 & 3.8 & 41.86 & 1.33 & 7.35 & 1 \\
\hline \hline 4.98 & 85.5 & 8.46 & 1037 & 160 & 0 & 26.6 & 26.8 & 2.07 & 7.18 & 2 \\
\hline \hline 105 & 84.6 & 8.85 & 827 & 630 & 0 & 14 & 17.8 & 1.65 & 7.38 & 3 \\
\hline \hline 32 & 78.2 & 8 & 1662 & 530 & 0 & 17.26 & 23.12 & 3.32 & 7.5 & 4 \\
\hline \hline 90 & 78.3 & 7.95 & 2175 & 360 & 0 & 19.86 & 24.2 & 4.35 & 7.6 & 5 \\
\hline \hline 7.45 & 82.1 & 8.45 & 1701 & 500 & 0 & 17.12 & 25.66 & 3.40 & 7.6 & 6 \\
\hline \hline 13.01 & 79.4 & 8 & 1477 & 600 & 0 & 31.6 & 30.32 & 2.95 & 7.5 & 7 \\
\hline \hline 0.05 & 79.6 & 8.15 & 1157 & 530 & 0 & 7.06 & 23.8 & 2.31 & 7.7 & 8 \\
\hline \hline 1.35 & 78 & 7.78 & 1648 & 430 & 0 & 3.12 & 43.26 & 3.29 & 7.7 & 9 \\
\hline
\end{tabular}

Bicarbonate highest value was $630 \mathrm{meq} / 1$, and its lowest value was $160 \mathrm{meq} / 1$. The reason of these high values is due to the presence of sedimentary rocks in addition to its primary sources of minerals and carbonate.

Contour maps were drawn to illustrate the distribution of $\mathrm{pH}, \mathrm{EC}, \mathrm{Cl}$ and $\mathrm{HCO}_{3}$ concentrations. Through these maps, it is possible to know the locations of high and low concentrations of the physical and chemical properties of the 
studied wells, as well as known the distribution of the values of these properties in general in the studied area, Figure (3).
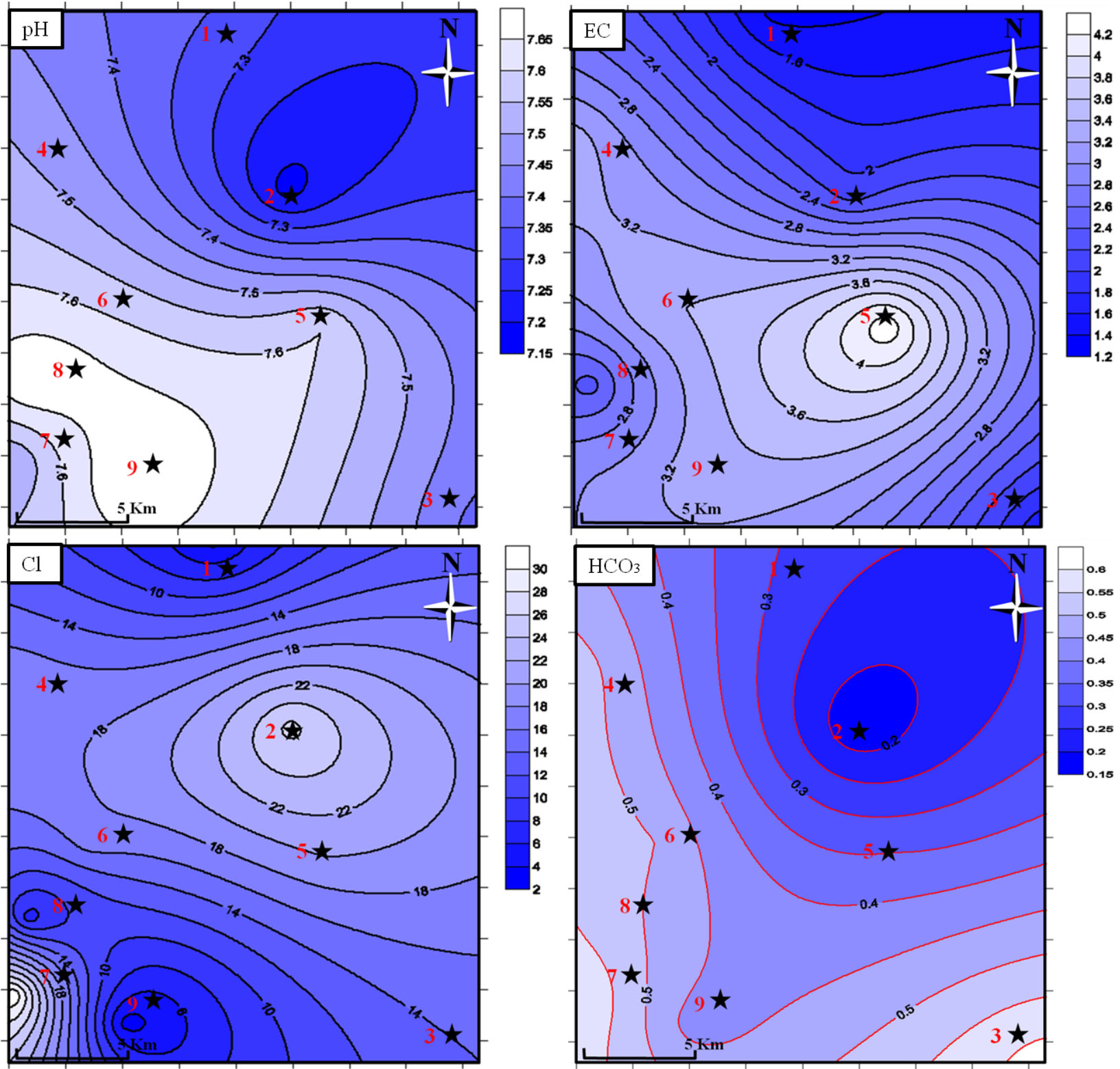

Figure (3) shows the contour maps for the distribution of the chemical properties and the concentration of some ions values in the water well of the study area, the upper left side represents the $\mathrm{pH}$ distribution map in the region, the upper right side represents the EC distribution map, the lower left side represents the distribution map of the $\mathrm{Cl}$, and the lower right hand side represents the distribution map of $\mathrm{HCO}_{3}$ ion in the well waters of the study area. The black stars represent the wells locations. Each symbol is the well number, while the letter $\mathrm{N}$ and the arrow represent the north direction. 
Also, TDS was estimated for the well water, its highest value was $2175 \mathrm{ppm}$ and its lowest value was $666 \mathrm{ppm}$, This is due to the high concentration of ions as a result of its long stay with rocks, as well as reasons related to the geological nature and the salt content of the lands that where the wells were excavated (SDWF, 2008). When comparing the results of TDS with Table No. (3), which shows the classification of water according to its content of TDS based on (Todd, 1980), it was found that well No. (1) was of the fresh type, and the rest of the wells were of the brackish type.

Table (2) Classification of water according to its TDS content based on (Todd, 1980)

\begin{tabular}{|c|c|}
\hline Water class & Ppm \\
\hline \hline Fresh & $0-1000$ \\
\hline \hline Brackish & $1000-10000$ \\
\hline \hline Saltine & $10000-100000$ \\
\hline \hline Brine & $>100000$ \\
\hline
\end{tabular}

The turbidity was also estimated, and its highest value was 105 FTU, and its lowest value was 0.05 FTU, the reason for this was due to its passage in the natural filtration process through the earth's layers (EPA, 2005)

Calcium concentration was also studied for well water, and the highest value was $41.86 \mathrm{meq} / 1$ and the lowest value was $17.8 \mathrm{meq} / 1$. The reason is the solubility of limestone in water (Al-Adli, 1992), as well as the difference in concentration of calcium in water resources and depending on the geological composition and the type of the salts that make up the soil surrounding the well, Iraqi soils are of a limestone nature (Buringh, 1960).

DO was measured, its highest value was $8.85 \mathrm{ppm}$ and its lowest value was $7.30 \mathrm{ppm}$, these measured values were appeared for several reasons, Kostamo,2008 denoted to the ratio of oxygen solubility in water decreases with increasing of the water temperature (Kostamo,2008). Also the water speed, wind speed and rain will affect the DO values (Al-Zubaidi, 1985; Al-Araji, 1988). The concentration of DO depends on the natural and biological chemical activities in the human body, and its scale indicates a good indication of the quality of the water.

Contour maps were drawn to plot the distribution of TDS, TUR, Ca and DO concentrations. Through these maps, it is possible to know the locations of high and low concentrations of the physical and chemical properties of the wells in the study area, as well as know the distribution of the values of these properties in general in the studied area (Figure 4). 

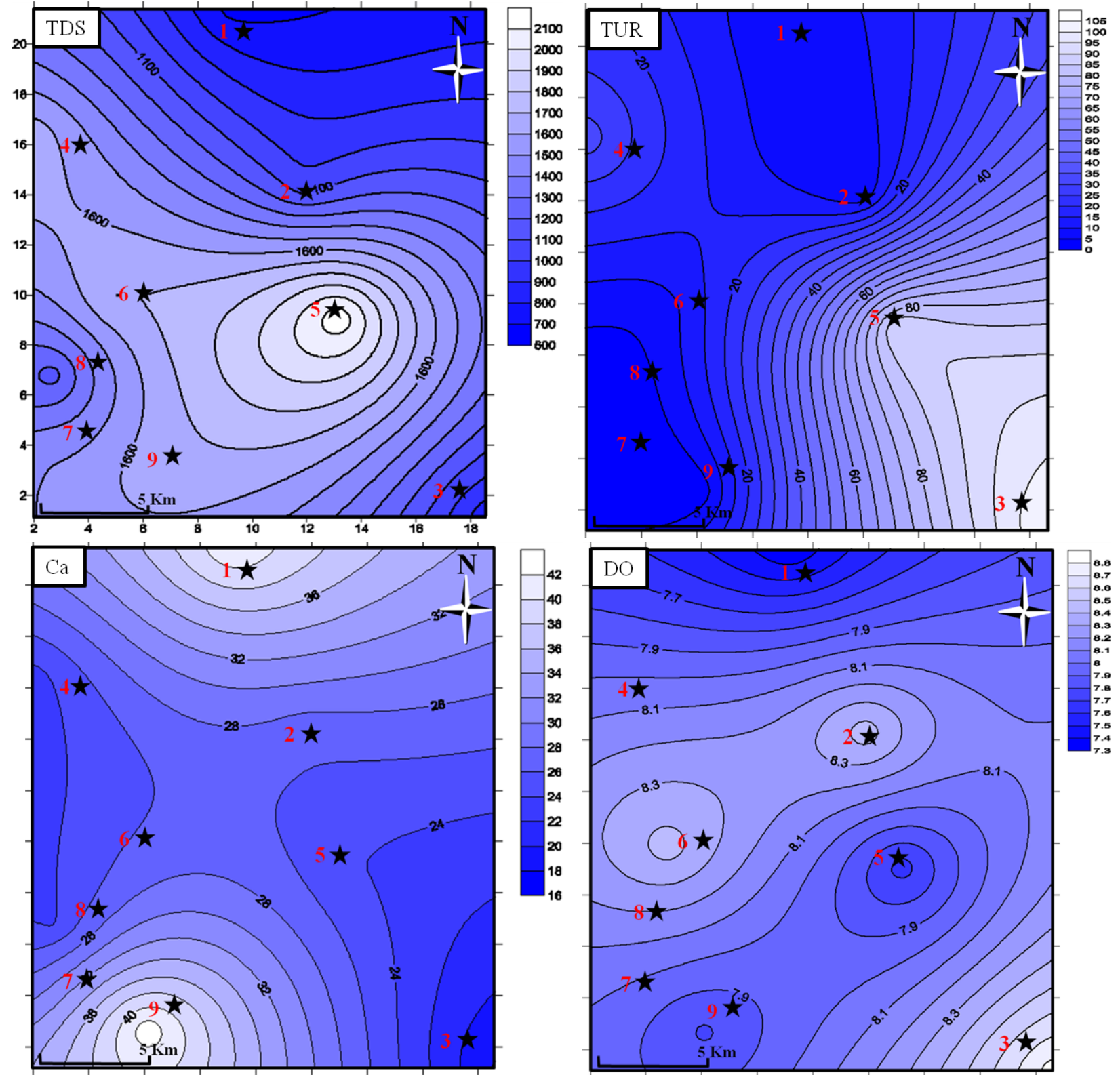

Figure No. (4) shows the contour maps for the distribution of the values of chemical properties and the concentration of some ions in the well water of the study area, the upper left side represents the TDS distribution map, the upper right side represents the TUR distribution map, the lower left side represents the distribution map of the Ca, the lower right hand side represents a map of the distribution of DO in the well water of the study area. The black stars represent the well locations. There is the well number on each symbol, while the letter $\mathrm{N}$ and the arrow below it represent the north direction of the study area. 
When comparing the results obtained in table (2) for calcium with the specifications of the World Health Organization (Table No. 4), it was found that the percentage of calcium in all wells exceeds these specifications. When comparing the chlorine results with WHO specifications, it was found that the chlorine percentage in all wells was higher than the limit, except for the wells $(1,8,9)$ that were in conformity with the specifications.

Table No. (4) The limits of the concentrations of positive and negative ions and salinity according to the specifications of World health Organization (WHO, 1996)

\begin{tabular}{|r|r|r|r|r|}
\hline Unit & $\mathrm{Ca}$ & $\mathrm{Cl}$ & $\mathrm{HCO}_{3}$ & $\mathrm{TDS}$ \\
\hline \hline $\mathrm{Ppm}$ & 75 & 250 & $350-125$ & $1000-500$ \\
\hline
\end{tabular}

By comparing the bicarbonate results with the WHO specifications, the results exceeded the limits in all wells. When comparing the TDS results of the samples with the WHO specifications, it was found that only the wells $(1,3)$ are within the limit and the rest of the wells are exceed the limits of the specifications.

Table No. (5) Comparison of water specifications in the study area with the Iraqi standards IQS, 2009);

((WHO,1996)

\begin{tabular}{|c|c|c|}
\hline WHO & Iraqi standards, (IQS),2009) & Elements \\
\hline \hline 75 & 50 suitable & $\mathrm{Ca}$ \\
\hline \hline 250 & 250 suitable & $\mathrm{Cl}$ \\
\hline \hline 1000 & 1000 suitable & TDS \\
\hline \hline $6.5-8.5$ & $6.8-8.5$ suitable & $\mathrm{pH}$ \\
\hline
\end{tabular}

When comparing the calcium results with the above table (Table No. 5), it was found that all wells are out of the limitation of the IQS and WHO specifications. When comparing the chlorine results with the same table, it was found that only the wells $(1,8,9)$ are within the limitations with the above specifications. When comparing the results of TDS with the table above, it was found that only wells $(1,3)$ are applicable with the above specifications. When comparing the $\mathrm{pH}$ results with the above table, it was found that all wells meet the above specifications. 
University of Thi-Qar Journal of agricultural research

ISSN Onlin:2708-9347, ISSN Print: 2708-9339 Volume 10, Issue 1 (2021) PP 131 -148

https://jam.utq.edu.iq/index.php/main $\quad \underline{\text { https://10.54174/UTJagr.Vo10.N1/13 }}$

Table No. (6) Specifications of water for animal consumption (Altoviski, 1962)

\begin{tabular}{|c||c|c|c|c|c|}
\hline Ions & $\begin{array}{c}\text { Very good } \\
\text { water }\end{array}$ & $\begin{array}{c}\text { Good } \\
\text { water }\end{array}$ & $\begin{array}{c}\text { Permissible water to } \\
\text { use }\end{array}$ & Can be used & $\begin{array}{c}\text { The upper } \\
\text { limit }\end{array}$ \\
\hline \hline Ca ppm & 350 & 700 & 800 & 9000 & 1000 \\
\hline \hline Cl ppm & 900 & 2000 & 3000 & 4000 & 6000 \\
\hline \hline TDS ppm & 3000 & 5000 & 7000 & 10000 & 15000 \\
\hline \hline TUR ppm & 1500 & 3200 & 4000 & 4700 & 54000 \\
\hline
\end{tabular}

When comparing the results of Well No. 1 in table (2) with the (Ca, Cl, TDS, TUR) values in table (6), it was found that water of the well (1) can be used for animal consumption, either the wells $(2,3,4,5,6,7,8)$, the water quality was good for animal use, while well No. (9), its water was permissible to use

Table No. (7)International, Iraqi and American standards for determining the suitability of drinking water (WHO, 2004).

\begin{tabular}{|c||c|c|c|}
\hline Factor & (USEA, 1975) & $\begin{array}{c}(\text { lQS, 1996) } \\
\text { mlg. } .^{-1}\end{array}$ & $\begin{array}{c}\text { (WHO,1990) } \\
\text { mlg. } .^{-1}\end{array}$ \\
\hline \hline TDS & 500 & 1000 & 1000 \\
\hline \hline $\mathrm{pH}$ & & $6.5-8.5$ & $6.5-9.5$ \\
\hline \hline $\mathrm{Ca}$ & 200 & 156 & 200 \\
\hline \hline $\mathrm{Cl}$ & 250 & 250 & 250 \\
\hline \hline $\mathrm{HCO}_{3}$ & 500 & - & - \\
\hline
\end{tabular}

When comparing the results with international, Iraqi and American standards, it was found that all water from wells is not suitable for human drinking.

\section{IV.CONCLUSION}

Water samples were collected from 9 wells in Al-Rifai city in Thi-Qar governorate / southern Iraq during the year 2020 for the purpose of assessing the quality of well water. The EC, pH, TDS, and turbidity were measured. The concentrations of some major ions in the water of these wells, represented by $\mathrm{Cl}, \mathrm{CO}_{3}, \mathrm{HCO}_{3}, \mathrm{Ca}$ and $\mathrm{DO}$, were also measured. When comparing the results of TDS with the classification of water based on (Todd, 1980), it was found that well No. (1) was of the fresh type, and the rest of the wells were of the brackish type. Comparing the calcium 
concentration with the specifications of the World Health Organization, it was found that the percentage of calcium in all wells exceeds these specifications. Also, comparing the chlorine results with the same specifications, it was found that the chlorine percentage in all wells was higher than the limit, except the wells $(1,8,9)$ which were in conformity with the specifications. By comparing the $\mathrm{HCO}_{3}$ values with the WHO specifications, all values exceeded the limits in all wells. Also, comparing the TDS results of the samples with the same specifications, it was found that only the wells $(1,3)$ are within the limit and the rest of the wells are exceed the limits of the specifications. When comparing the Ca results with the ISR and WHO specifications, it was found that all wells are out of the limitation; $\mathrm{Cl}$ results showed that only the wells $(1,8,9)$ are within the previous limitations. TDS values of only wells $(1,3)$ are applicable with the above specifications. All $\mathrm{pH}$ results for all wells meet the ISR and WHO specifications. Comparing ( $\mathrm{Ca}, \mathrm{Cl}$, TDS, TUR) values with the specification of water for animal consumption in (Altovisiki, 1992), it shows that water of the well (1) can be used for animal consumption, either the wells $(2,3,4,5,6,7,8)$, the water quality was good for animal use, while well No. (9), its water was permissible to use When comparing the obtained results with international, Iraqi and American standards, it was found that all water from wells is not suitable for human drinking.

\section{Recommendations}

Researchers recommend the following:

1-Expand the number of study wells and increase the studied parameters.

2- Deliver these results to the relevant authorities to benefit from.

3- Conducting awareness programs on the well water quality and use for the rural areas.

\section{REFERENCES:}

1. Abed, K. F. and Al Wakeel, S. S. 2007. Mineral and microbial content of bottled and top water in Riyadh in Saudi Arabia. Middle East Journal of Scientific Research. 2(3) :151-156.

2. Adam, G. A. 1983. Industrial Pollution. Basra University Press, Iraq. 300 pages, in Arabic

3. Al-Adli, Aqil Shaker Ghani, 1992. Human activities on the quality of the water of the Lower Diyala River. Master Thesis, College of Science, University of Baghdad. 108 pages, in Arabic.

4. Al-Obeidi, Nabil Muhammad Ali, and Ajam, Ali Falih, 1989. (Industrial Chemistry and Its Raw Materials) Basra University Press, First Edition. 622 pages, in Arabic

5. Al-Saadi, H. A., T. I. Kassim,, Al-Lami and S. K. Salman (2000). Spatial and Seasonal Variations of Phytoplankton Populations in the Upper Region of the Euphrates River, Iraq. Limnologica - Ecology and Management of Inland Waters, Vol. 30(1):83-90. DOI: 10.1016/S0075-9511(00)80049-3.

6. Altovisiki, M. E., 1962: Hand book of hydrogeology. Geogoelitzet, Moscow, USSR, 614p. 
7. Al-Zamili, T.F. and Al-Shahmani , H. K. 2005. Evaluation of environmental and geological parameter for ground water in Am-Auneej in Thi-Qar. Journal of Qadasia,Pure Sciences, 10 (1):131-138, in Arabic

8. Al-Zubaidi, Abdul-Jalil Muhammad (1985). An environmental study on algae (phytoplankton) for some marsh areas near Qurna - southern Iraq. Master Thesis, Basra University, College of Science, 236 pages, in arabic

9. Appelo,C. A. J. and Postma, D.,1999 Geochemistry, Ground water and pollution, A.A. Balkema Publisherd,536 pages.

10. Buringh , P. 1960 . Soils and Soil Conditions in Iraq. Ministry of Agriculture, Baghdad, Iraq, 322 pages.

11. Camp, R. L. and Meserve, R. L. 1974. Water and its Impurities. Dowden, Hutchinson \& Ross Inc., U.S.A.

12. Detay, M., Water Well-Implementation, Maintenace Restoration, John Wiley \& Sons, Baffins Lane, Chichester, London, 1997.

13. Environmental Protection Agency (EPA). 2005. Water Health Series: Bottled Water Basics.10 pages.

14. Haddad, R. H. 1978. Study the Ground Water Quality in Manchester City. England, PhD. Dissertation, University of London.

15. Hassan, F. M. (2004). Limnological Features Diwanyia River, lraq .Journal of Um-Salama for Science. $1(1): 1-6$

16. Hassan, F. M. 2004. Limnological features Diwanyia River, lraq. Journal of Um-Salama for Science. 1(1):1-6

17. Hem, J. D. 1989. Study and Interpretation of the Chemical Characteristics of Natural Water, 2nd Edition, U.S.G.S. Water Supply, Washington D. C., No.147.

18. Hem, J. D., (1970).Study and Interpretation of the Chemical Characteristics of Natural Water. U.S. Geological Surveys water Supply paper 2254, 246 pages.

19. IQS, Iraqi Quality Standard, 2009: Drinking water, Standard No. 417, C. O. S. Q. C., Iraq.

20. Jassim, S.Z. and Goff, J.C. 2006. Geology of Iraq. First edition. Dolin, Prague and Moravian, Brno. Czech Republic. 341 pages.

21. Kostamo, J (2008). Detecting Microbial Contaminants in Drinking Water. In: Advanced Studies in Environmental Microbiology and Biotechnology Ecological Sanitation and Manure Treatment as Tools to Improve Water Hygiene. Edited by, Tanski, H, H., University of Kuopio, Finland.19-23.

22. Langmuir. D. 1997. Aqueous Environ mental Geochemistry. Prentice Hall. USA, 600 pages.

23. Mazor. E. ,1990, Applied Chemical and Isotopic Ground Water Hydrology, Wiley, New York, 274 pages.

24. Naseem, M. G. 2007. Analysis and Evaluation of Water Quality. Al-Quds, Alexandria Press, 179 pages, in Arabic

25. Safe Drinking Water Foundation (SDWF). 2008 .TDS \& pH. Safe Drinking Water Foundation, 6 pages. 
26. Shamran, A. R.. 2016. Detection of Rotavirus in pumps water, tanks water and tab water samples in Babylon province. Euphrates Journal of Agriculture Science. 8 (1): 149-153, in Arabic

27. Todd, D. K.,1980.Ground Water hydro logy ,John Willey, New York, 535 pages.

28. Todd, D. K.,1980.Ground Water hydrology ,John Willey, New York, 535 pages.

29. World Health Organization (WHO), 1996. International standard for Drinking Water , Geneva, Switzerland,70 pages. 